\title{
Assessment of Gas Hydrate Resources in Ross Sea Area, Antarctica Based on Inversion of Gravity and Magnetic Data
}

\author{
wei Wang ( $\sim$ wang_w20@hdec.com ) \\ Zhejiang Huadong Construction Engineering Co.,Itd \\ meng Wan \\ Zhejiang Academy of Surveying and Mapping \\ miaojun Sun
}

Powerchina Huadong Engineering Corporation LIMITED

weijie Jiang

Zhejiang Huadong Construction Engineering Co.,Itd

ping Xu

Zhejiang Huadong Construction Engineering Co.,Itd

\section{Research Article}

Keywords: Magnetic, Gravity, Curie, Moho, heat flow, gas hydrate

Posted Date: December 21st, 2021

DOl: https://doi.org/10.21203/rs.3.rs-125206/v2

License: (c) (i) This work is licensed under a Creative Commons Attribution 4.0 International License. Read Full License 


\title{
Assessment of gas hydrate resources in Ross Sea area, Antarctica based on inversion of gravity and magnetic data
}

Wang Wei, ${ }^{1,2,}$, Wan Meng ${ }^{3}$, Sun Miaojun ${ }^{1,2}$, Jiang Weijie ${ }^{1,2}$, Xu Ping ${ }^{1,2}$,

* Correspondence: 11438025@zju.edu.cn(W.W.)

\begin{abstract}
The Ross Sea is located between Victoria Land and Mary Bird Land in West Antarctica. In this paper, the published gravity and magnetic data in the Ross Sea area are fused with the high-precision gravity and magnetic data measured by the ship. Then, The gravity anomaly data is used to invert the Moho depth by the Parker-Oldenburg method; the magnetic anomaly data is used to invert the Curie depth of the Ross Sea area by the power spectrum method. Finally, according to the inversion results of the Moho depth and Curie depth, the high-precision heat flow distribution in the Ross Sea area is calculated. And compared with the actual measured heat flow value and other inversion results, it shows that this inversion result has obtained a higher resolution. At the same time, the geothermal gradient is calculated by heat flow and thermal conductivity. According to the temperature-pressure equation for formation and storage of gas hydrate, the thickness of the gas hydrate stability zone in the study area was quantitatively calculated.
\end{abstract}

Key Words: Magnetic; Gravity; Curie; Moho; heat flow; gas hydrate

\section{Introduction}

Gas hydrate is mainly cage-like and ice-like crystals formed by the combination of methane and other gas molecules and water molecules under the condition of low temperature and high pressure. In the ocean, it generally occurs in continental marginal, continental shelves, continental slopes, underwater highlands and marginal seabed sediments below 500m water depth, especially those sedimentary basins related to mud volcano, diapiric structure and large fault (A K K, 1988; Dou Shi, et al. 1992 ). It is estimated that the total global gas hydrate resources are $2 \times 10^{16} \mathrm{~m}^{3}$, which is equivalent to twice the total carbon content of proven oil, natural gas and coal(S C T, 2002; Youhai Z, et al. 2001 ).

Gas hydrate is an unstable solid substancel(Moscardelli L, et al. 2006). Under suitable thermal conditions, gas hydrate itself will continue to decompose (Shuan Shi F, et al., 2007). Due to the shallow burial depth, under normal circumstances, cap rocks with low permeability are rarely trapped above gas hydrate. The accumulation of gas hydrate mainly depends on the constraints of temperature and pressure 
conditions(Lifeng W, et al., 2013). Therefore, temperature and pressure conditions are very important for the analysis of gas hydrate accumulation.

In this paper, based on the magnetic data inversion of the heat flow distribution in the Ross Sea, the accumulation conditions of this area are analyzed with(by using) the temperature, pressure and thermal factor(data). The thickness of the gas hydrate stability zone is calculated, and the resource prospect of gas hydrate in this area is preliminarily estimated by volume integral method.

\section{Overview of the study area}

Ross Sea is a large bay located in the fan-shaped area on the Pacific side of Antarctica. The geographical coordinates are between $72^{\circ} \mathrm{S} \sim 85^{\circ} \mathrm{S}, 160^{\circ} \mathrm{E} \sim 160^{\circ}$ $\mathrm{W}$. The width of the continental margin is about $850 \mathrm{~km}$ and the length is about 1,500 $\mathrm{km}$. As about half the width of the continental shelf is covered by glaciers all year round, so it is usually referred to as the northern end of Ross Bay(figure 1). Ross Sea lies west of the Trans-Antarctic Mountains and Victoria Land, east of Marie Byrd Land, and ice bodies slipping down from its southern continent form the Ross Ice Shelf. The topography of the seabed has the characteristics of high north(shallow) and low(deep) south, that is, deepening toward the Ross Ice Shelf from the outside to the inside (Cooper, Davey \& Hinz, 1988). The Multichannel seismic (MCS) survey of the Ross Sea after 1980 clearly reflects the characteristics and scope of the submarine rift structure. MCS data reveals that the Ross Sea has three main deposition centers: the Victoria Land Basin (VLB), Central Trough(CT) and Eastern Basin(EB)(Y K \& K H, 1991). The Victoria Basin is structurally more complicated than other basins. It is composed of some sub-basins and graben, and may extend hundreds of kilometers below the Ross Ice Shelf. The Northern Basin(NB) and Northern Central Trough(NCT) seem to be the continuation of the strike of the Victoria Land Basin(VLB) and Central Trough(CT), respectively The maximum deposition thickness in the Terra Rift(TR) is up to $14 \mathrm{~km}$ (Davey F J, et al., 1982; Cooper, Davey \& Behrendt, 1987a). 


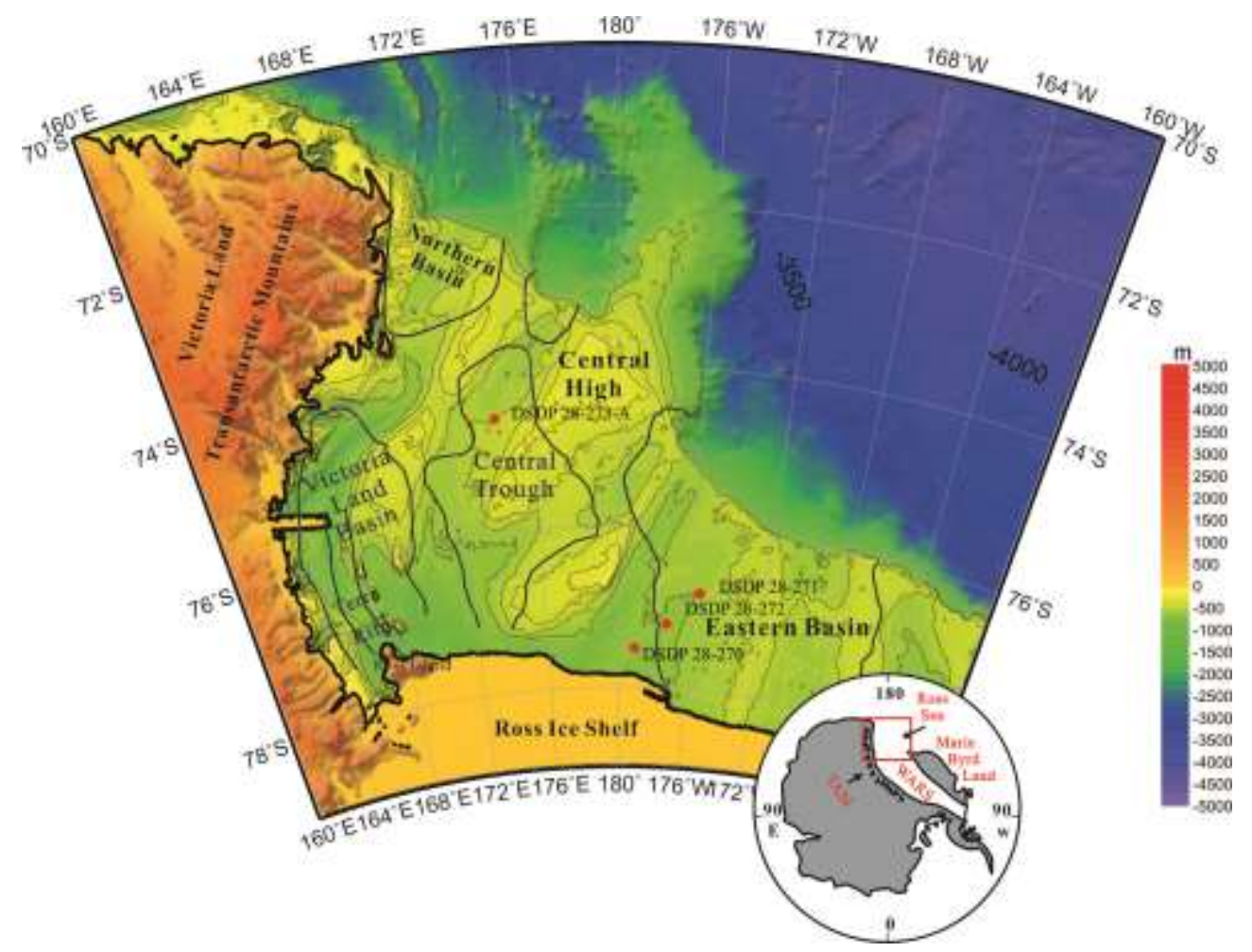

Fig.1 Topography/bathymetry of the Ross Sea, the TAM and adjacent areas. The Thick black solid line represents the coastline of Victoria Land. The thin black solid line represents the basin structure. Red points indicate DSDP drilling (Houtz et al., 1972)

The investigation and research of gas hydrates on the continental margin of Antarctica began in the 1970s. MCIVER(Mciver R D, 1975) first reported the existence of gas hydrates on the continental margin of Antarctica. The geochemical conditions of the Antarctic continental margin basin are conducive to the accumulation of gas hydrates. During the DSDP28 voyage, three drill cores of 271, 272, and 273 were obtained in the Ross Sea. Among them, a high content of total hydrocarbon gas of up to $179000 \mathrm{uL} / \mathrm{L}$ (mainly Methane)(Geletti R and Busetti M, 2011). In the two gravity corer samples collected near the DSDP273 well site, the methane volume fraction was $3 \sim 6.7 \mathrm{uL} / \mathrm{L}$, but the methane volume fraction in the deep sediments of the DSDP273 well site reached $52000 \sim 146000 \mathrm{uL} / \mathrm{L}$, indicating high content of methane does not reach the near-surface sediments (Geletti R and Busetti M, 2011). Both MCIVER (Rapp J B,) (Mciver R D, 1975) and RAPP (Rapp J B, 1987) infer that this gas may be immobilized like gas hydrate. 


\section{Temperature-pressure conditions for the formation of gas hydrate}

FARADAY (1823) and VILLARD(1896) carried out research work on the hydrate temperature-pressure equation earlier. They found that temperature and pressure are two very important factors that control the formation of hydrates. Their research shows that a variety of gases can form hydrates under suitable temperature-pressure conditions. KOBAYASHI et al. (1949) and KVENVOLDEN et al.(1980) conducted a more detailed study on the conditions of gas hydrate formation and stable storage, and revised the temperature and pressure condition curves obtained by FARADAY(1823) and VILLARD(1896). Figure 2 is an analysis diagram of temperature-pressure conditions processed on the basis of the temperature-pressure curves of KOBAYASHI et al.(1949) and KVENVOLDEN et al.(1980).

As shown in Figure 2, the abscissa represents the temperature, and the ordinate represents the water depth and the corresponding pressure. The gray part of the picture can form natural gas hydrate. But for the marine environment, the part below the freezing point is not analyzed. It can be seen from Figure 2 that the lower the seabed temperature, the lower the pressure required to form hydrates; the deeper the water, the higher the temperature at which the corresponding hydrates can exist stably.Antarctica is the coldest continent on earth. Its average temperature in January in summer is minus a few degrees Celsius, and in July in winter it is minus 20 degrees Celsius (Barker P F et al.,1999), while the seabed temperature of Antarctica is lower than that in other regions. The measured seabed temperature of ODP178 voyage 1095 hole (Lee M W et al.,1993) and ODP188 voyage 1165 hole ( Cooper A K and PE O'Brien ,2004 ) are both lower than $0{ }^{\circ} \mathrm{C}$. The latitude of the Ross Sea is between $72^{\circ} \mathrm{S}$ and $85^{\circ} \mathrm{S}$, which is higher than the latitude of other continental seas except the Weddell Sea. The Ross Sea shelf area is affected by the erosion of the continental ice sheet, and the shelf water depth is much deeper than that outside the Antarctic continent. This causes the seabed pressure of the Ross Sea shelf to be much higher than other marginal sea areas, corresponding to the seabed temperature much lower than other sea areas., The Ross Sea area is easier to meet the stable occurrence conditions of hydrates. 


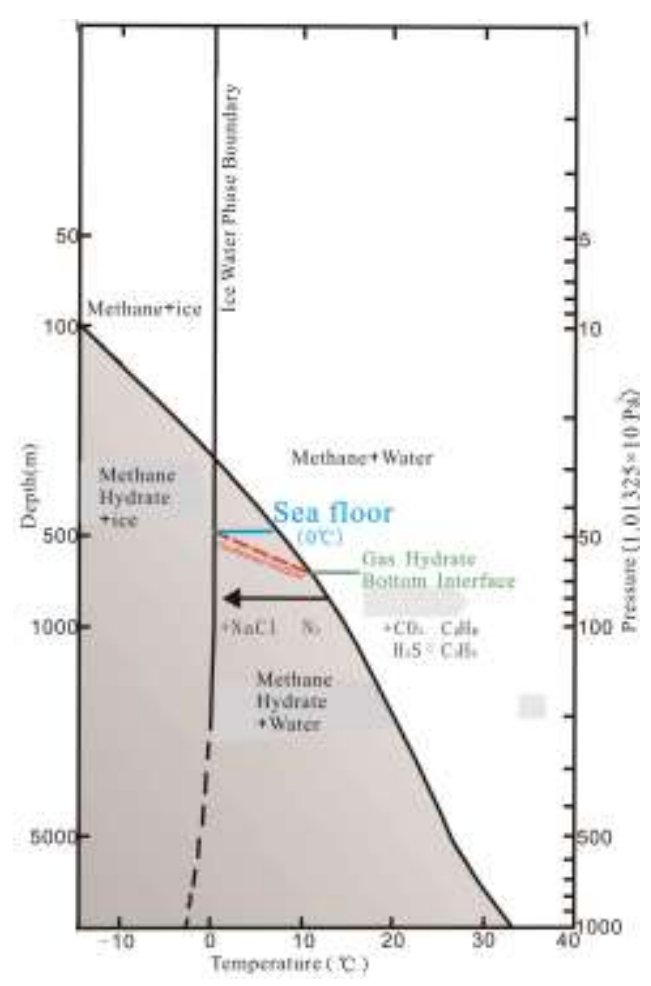

Fig.2 Temperature-pressure conditions analysis chart of gas hydrate (KOBAYASHI et al.,1949; KVENVOLDEN et al.,1980)

\section{Gravity and magnetic inversion thermal structure of Ross Sea}

\subsection{Data Sources}

The topographic data used the data from the ETOPO1 satellite altimetry inversion released by the National Oceanic and Atmospheric Administration (NOAA) in August 2008.

The magnetic data comes from the latest public data from the South Pole Geomagnetic Survey Project ADMAP. At the end of 2000, ADMAP has compiled a global magnetic anomaly grid with a resolution of $5 \mathrm{~km}$.

Gravity data is mainly used for Moho inversion. The gravity anomaly uses the 23 version data of Sandwell et al..

The heat flow data is downloaded through the "Global Heat Flow Database of the International Heat Flow Committee". 


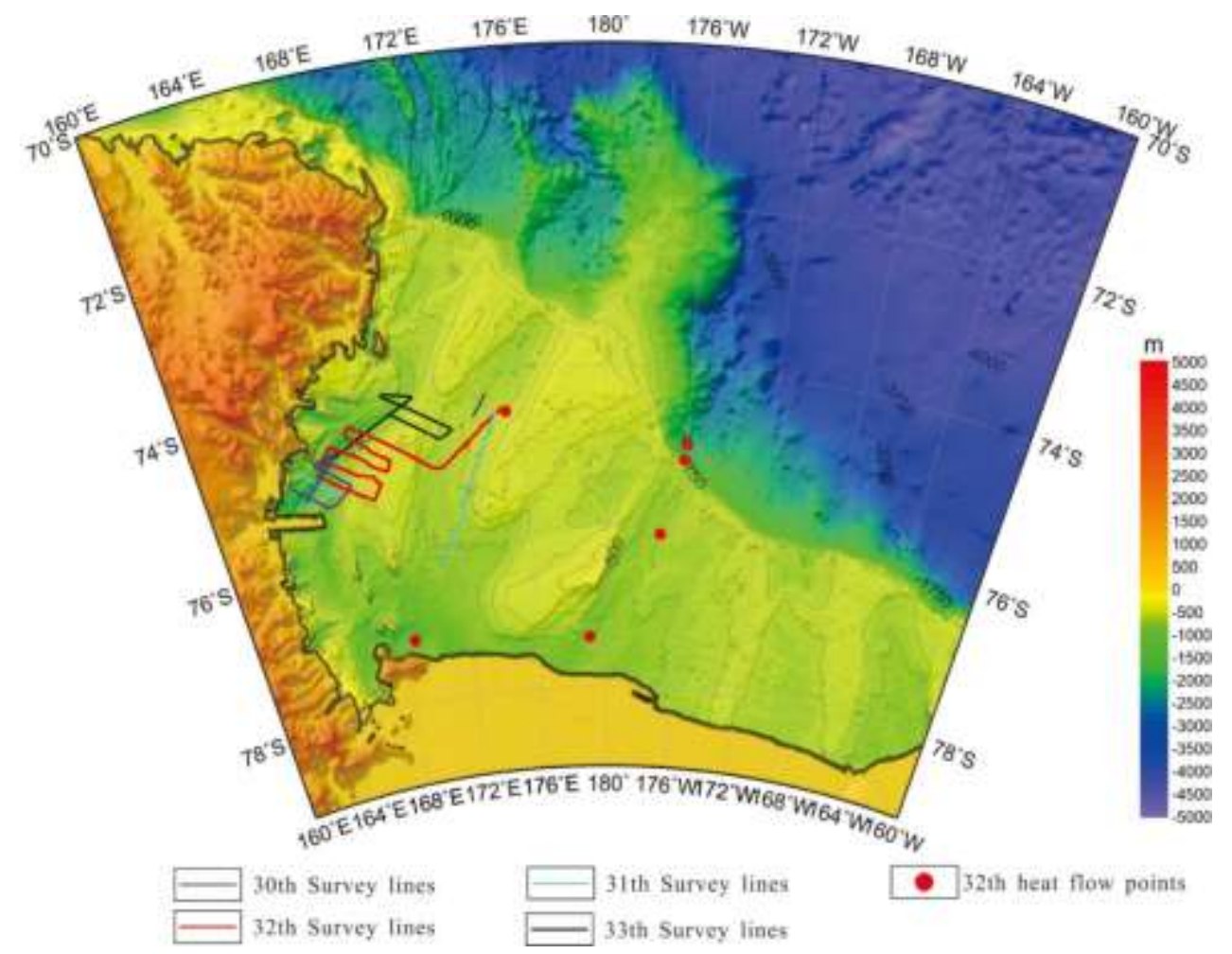

Fig.3 Survey lines and stations in the Ross Sea area of previous Antarctic scientific expeditions

In addition to the above data, through the accumulation of many Chinese Antarctic scientific expeditions, a considerable amount of geophysical data has also been accumulated in the Ross Sea area, which has been processed and calculated and combined with public data for use. Figure 3, the previous Ross Sea scientific expedition survey lines in Antarctica, each survey line has carried out water depth, gravity and magnetic measurement, most of which have carried out seismic survey and heat flow measurement.

\subsection{Gravity and magnetic inversion curie, Moho depth}

Heat flow is one of the most elusive geophysical observables, it is difficult to measure directly, and its measurement results are of poor regularity and have great variability (Davies, 2013). Li and Wang (2016) pointed out that the current understanding of the changes in the heat flow on the earth's surface is not sufficient to infer the deep thermal structure, and the Curie-point depth (CPD) derived from magnetic anomalies can be better constraint. Therefore, when there are difficulties in 
measuring the heat flow around the Antarctic surface, the amount of data is small, and it is difficult to truly reflect the internal thermal structure, the calculation of CPD becomes the best method for inversion of the thermal structure of the lithosphere.

CPD refers to the depth at which a magnetized material above a certain temperature becomes paramagnetic. In the crust, iron-titanium oxide (titanium magnetite) is the main source of magnetic anomalies (O'Reilly, 1976), and the Curie point temperature of magnetite is generally $580^{\circ} \mathrm{C}$. This boundary provides a key basis for calculating the distribution of heat flow in the Ross Sea. The calculated CPD change also needs to be compared with the obtained change in crustal thickness (CT).

\subsubsection{Magnetic anomaly inversion curie}

The wavelet multi-scale decomposition method is used to separate the magnetic anomaly information of the upper and lower interfaces of the magnetic layer, and the logarithmic power spectrum analysis is performed. Using the power spectrum method to invert the depth of the inner burial, the depth of the bottom surface of the magnetic layer, as the inner depth of the place, represents the average depth of the place, the inversion result is shown in Figure 4.

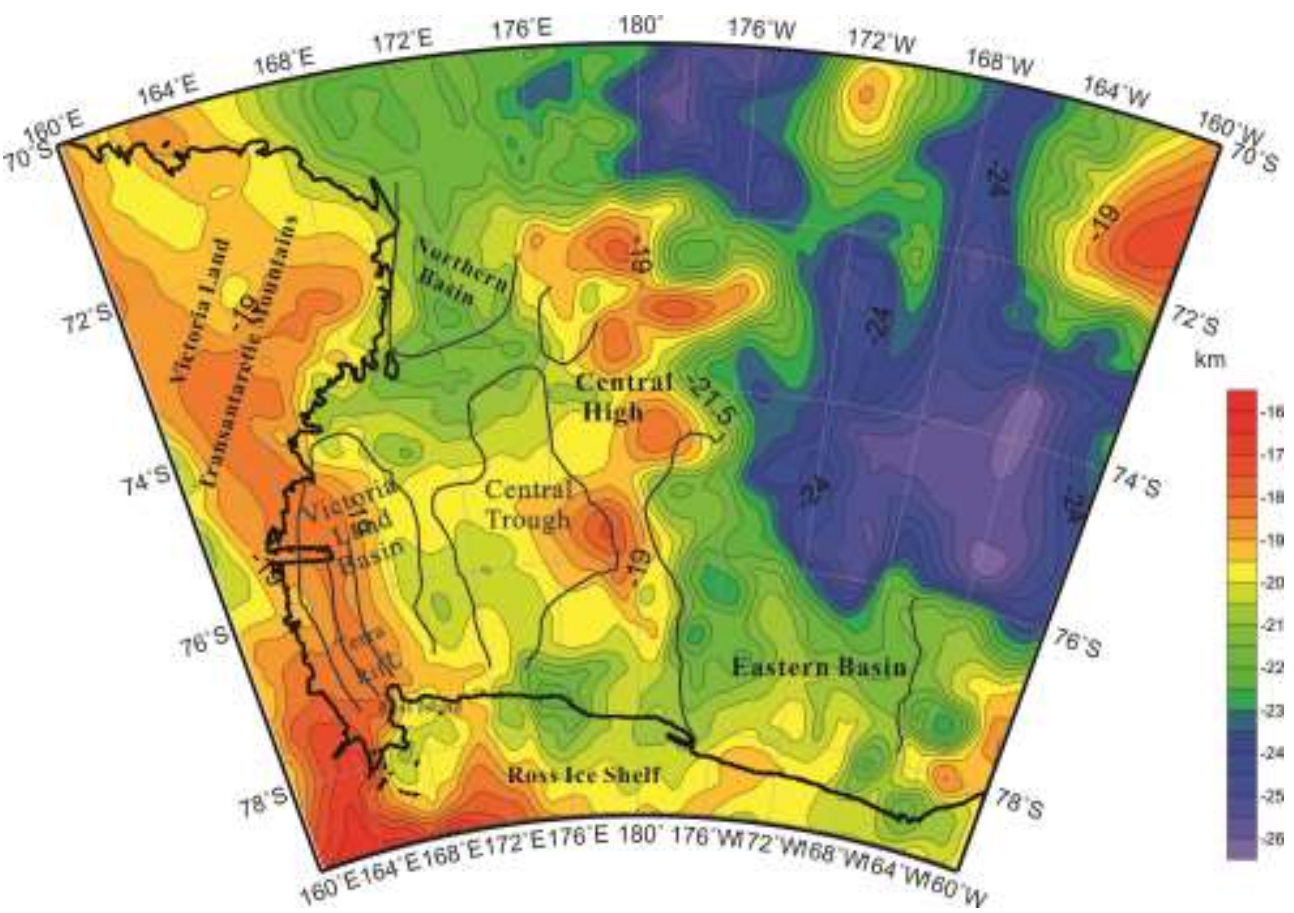

Fig.4 Curie-point depth distribution, contour line corresponds to the contour of CPD, black line represents geological unit 


\subsubsection{Gravity inversion Moho}

According to the iterative inversion equation proposed by Parker (1973)-Oldenburg (1974), the depth of the Moho in the study area is inverted in Figure 5.

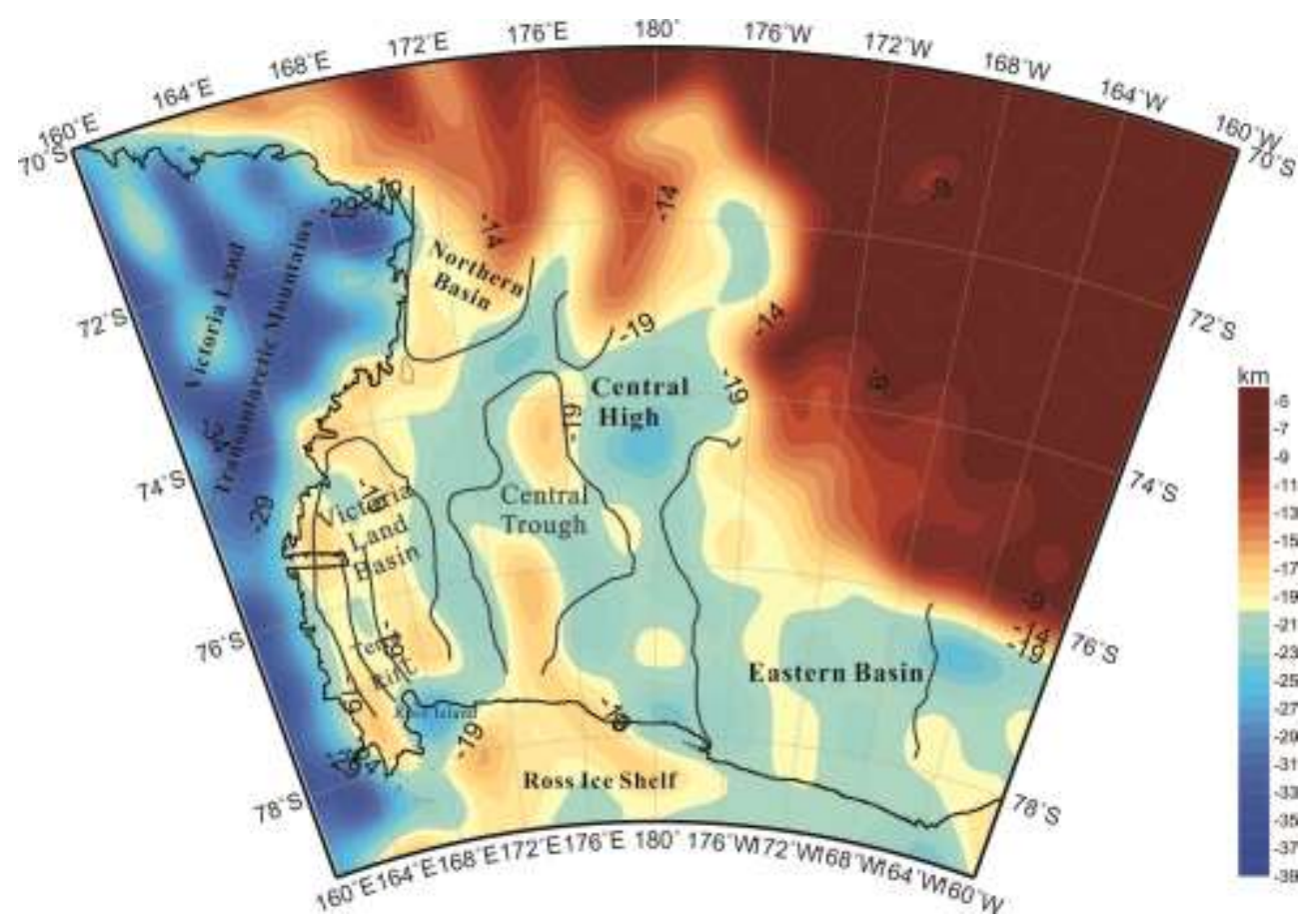

Fig.5 Moho depth distribution of Ross Sea, black line represents geological unit

\subsection{Heat flow calculation}

The heat flow Qo is calculated by CPD and CT. Suppose that under steady-state conditions, the surface heat flow consists of two parts: background heat and intra-layer heat generation from radioactive decay. According to Fourier's law, in the steady state the relationship between the one-dimensional surface heat flow $Q o$, the constant heat generation ( $A)$, constant thermal conductivity ( $k)$, surface temperature ( $T o$ ) and the temperature $(T z)$ at depth $(Z)$ is as follows:

$$
Q o=A \times Z / 2+\left(\begin{array}{cc}
T z & T o
\end{array}\right) k / Z
$$

In the formula, $T z=T c p d$ is the temperature of the bottom magnetic layer.

When CPD is higher than Moho, it is calculated as a single-layer problem: 


$$
Q o=A \times Z c p d / 2+(T c p d \quad T o) k c / Z c p d
$$

But when CDP is lower than Moho, the calculation is a two-layer problem (Figure 6):

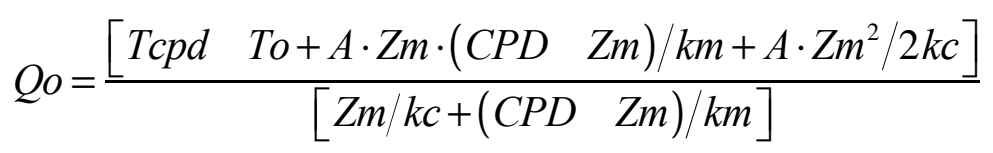

$\mathrm{Zm}$ is the depth of the Moho, $k c$ and $\mathrm{km}$ are the thermal conductivity of the crust and mantle, respectively.
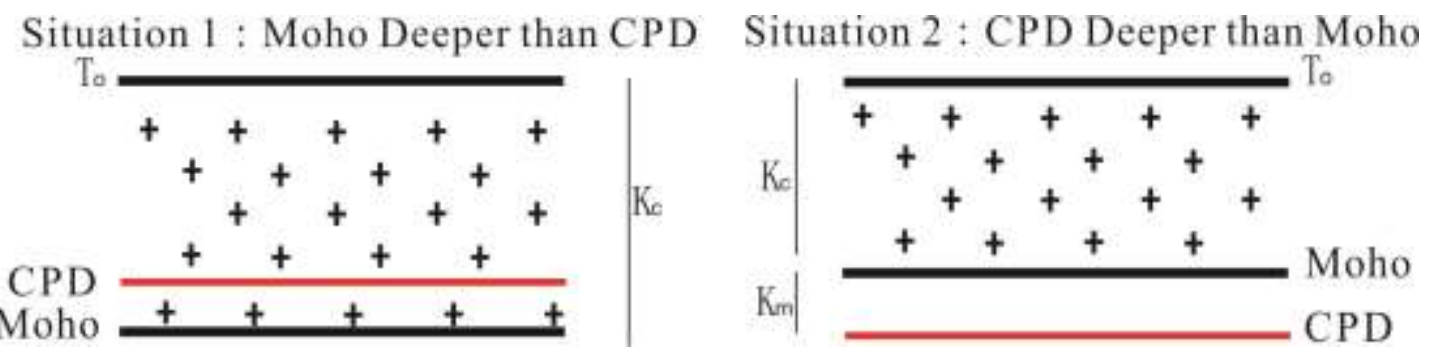

Fig.6 When Moho is deeper than CDP, the surface heat flow is calculated as a single-layer problem, and when the CDP is deeper than Moho, the surface heat flow is calculated as a two-layer problem. Assume that heat production (A) and thermal conductivity (crustal $k c$ and mantle $\mathrm{km}$ ) are constant.

For the crust and upper mantle, the thermal conductivity and radioactive crust thermal parameters are assumed to be constant. Moho is deeper than CPD, the thermal conductivity $2.2 \mathrm{~W} / \mathrm{mK}$ of the crust is taken as the average value of sediment, upper crust and lower crust. In areas where CPD is deeper than Moho, $2.7 \mathrm{~W} / \mathrm{mK}$ is used as the thermal conductivity of the upper mantle (Osako et al., 2010). Assume that the radioactive heat output of the crust is $1 \mu \mathrm{Wm}^{3}$ (Ramalho and FFernàndez, 1998), while the lithospheric mantle is zero.

As shown in Figure 7. The white line is the heat flow trend calculated by An et al. (2015). The red point is the heat flow point of the study area accumulated by the global heat flow database. In 2016, China's 32nd Antarctic Scientific Expedition measured $73.5 \mathrm{~mW} / \mathrm{m}^{2}$ heat flow at station RA05C. An et al. (2015) focused on the Antarctic continent. Their model has a higher resolution in calculating the heat flow in 
land areas, but has a very low resolution in ocean areas. The calculation results in this paper are more consistent with the results of An et al. (2015) on long wavelengths, and have higher resolution on short wavelengths. In the Ross Ice Shelf area, An et al. (2015) did not have an excessively high heat flow anomaly, but this paper calculated a higher heat flow anomaly, which is consistent with the calculation results of Maule et al. (2005). As the resolution of An et al. (2015) model is very low in ocean areas, it is obviously unable to satisfy the quantitative expression of basin-level heat flow. Compared with the seafloor heat flow values collected by the international heat flow database, many high heat flow anomalies are mainly concentrated in the area of $180^{\circ}$ longitude $77^{\circ} \mathrm{S}$ latitude, the southern end of the Victoria Basin and the central highlands, which are consistent with the high heat flow distribution calculated in this paper.

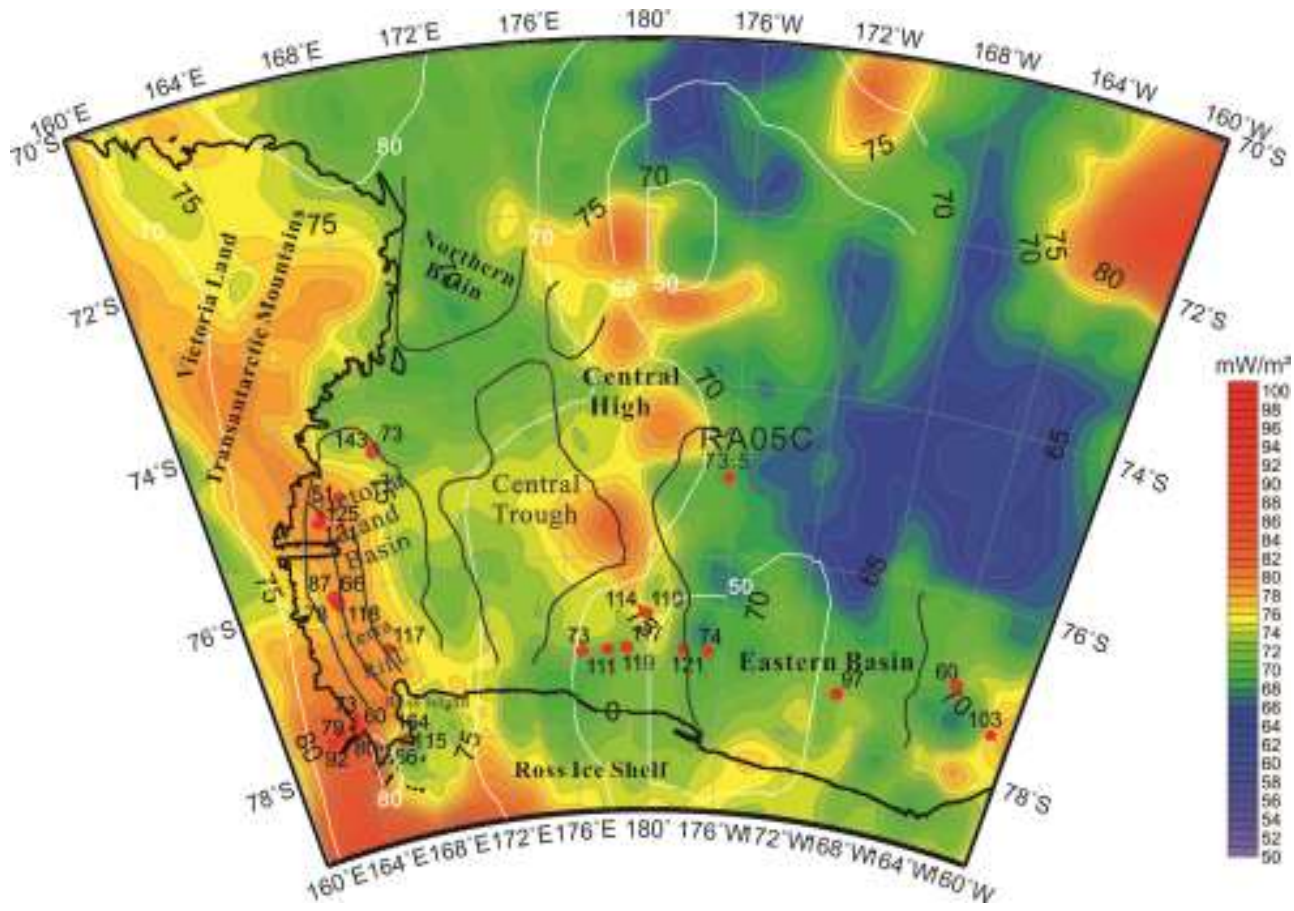

Fig.7 Anomalous distribution of heat flow in the Ross Sea area calculated by

CPD.The white line represents the heat flow value calculated by An et al. (2015). The red point is the measured value of heat flow on the seafloor surface accumulated in the Ross Sea area, and RA05C is the measured heat flow of the 32nd Antarctic Scientific Expedition in 2016. 


\section{Estimation of gas hydrate reserves in the Ross Sea}

Combined with the actual environmental conditions of the Ross Sea, and modified the pressure calculation equation and related assumptions of Milkov (2001), combined with the boundary curve equation of the methane hydrate stability zone in seawater proposed by Miles (1995) for calculation.

$$
P=2.8074023+a T+b T^{2}+c T^{3}+d T^{4}
$$

among them $a=1.559474 \times 10^{-1} ; \quad b=4.8275 \times 10^{-2} ; \quad c=-2.78083 \times 10^{-3} \quad ;$

$d=1.5922 \times 10^{-4}$ 。 $\mathrm{P}$ is the pressure value, the unit is $\mathrm{MPa}, \mathrm{T}$ is the temperature, the unit

is ${ }^{\circ} \mathrm{C}$. This assumption of static pressure is valid at shallow seabed depths, so when calculating the relationship between pressure and water depth, the hydrostatic pressure is used to approximate the actual seabed pressure:

$$
P=\rho_{1} g h+\rho_{2} g z
$$

Among them, $\rho_{1}$ is the seawater density, which is $1035 \mathrm{Kg} \cdot \mathrm{m}^{-3}, \mathrm{~g}$ is the acceleration of gravity, which is $9.81 \mathrm{~m} \cdot \mathrm{s}^{-2}, \mathrm{~h}$ is the water depth, and $\rho_{2}$ is the seabed surface sediment density, assuming $2000 \mathrm{Kg} \cdot \mathrm{m}^{-3}, \mathrm{z}$ is the thickness of the hydrate stabilizing layer in $\mathrm{km}$. The relationship between the bottom temperature of the stability zone where the hydrate is located and the geothermal gradient can be expressed by the following formula:

$$
T=t_{0}+(\Delta t / \Delta z) z
$$

Among them, the geothermal gradient $G=\Delta t / \Delta z$, The seafloor temperature in Antarctica is lower than that in other regions. The measured seafloor temperature of ODP178 voyage 1095 (Lee MW, 1993) and ODP188 voyage 1165 borehole are both lower than $0^{\circ} \mathrm{C}$. So the seafloor temperature is assumed to be $0^{\circ} \mathrm{C}, \mathrm{t}_{0}=0$.

According to the heat flow data Q of the Ross Sea area, the geothermal gradient $\mathrm{T}$ of the study area can be calculated. Above, we can calculate the thickness $\mathrm{z}$ of the gas hydrate stability zone (Figure 8). It can be seen that when the water depth is less than $276.5 \mathrm{~m}$, natural gas hydrate cannot be formed. 
This paper uses the following parameters to calculate: the average porosity of the sediment in the gas hydrate is $15 \%$, the saturation of the hydrate is 0.4 , the gas production factor is 150 , and the hydrate aggregation rate is 0.005 . The Byrd Basin is located under the ice shelf and is not counted here. The Ross Bay area also only counts the area inside the basin, and the rest are not included. The Victoria Land Basin(include NB) has an area of $80,000 \mathrm{~km}^{2}$, the Central Trough Basin has an area of $50,000 \mathrm{~km}^{2}$, and the Eastern Basin has an area of 100,000 $\mathrm{km}^{2}$. Calculated according to the basin's gas hydrate occurrence rate of $10 \%$, using volume fraction to calculate the gas hydrate occurrence within the three major basins of the Ross Sea, the available methane resource is $2.77 \times 1011 \mathrm{~m}^{3}$. This is $30 \%$ deviation from the calculation of Wang Wei et al. (2015). The 2015 calculation model relies heavily on the surface heat flow value, which is scarce in the Ross Sea area.

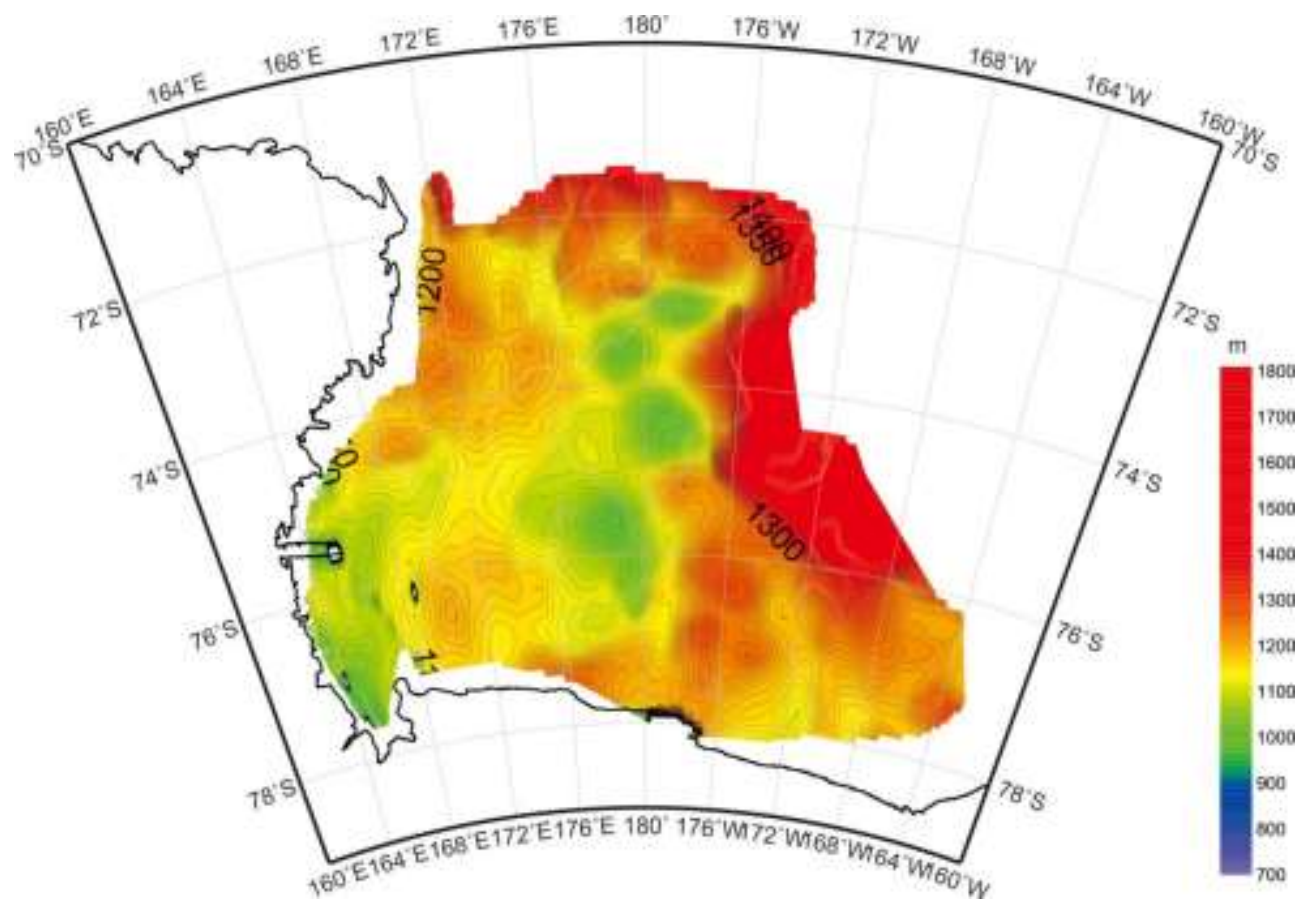

Fig.8 thickness of gas hydrate

\section{Conclusion}

(1) This paper calculates the inversion of the Moho and curie depth through gravity and magnetic data, and then inverts the thermal structure of the Ross Sea area.

According to the actual geology of the Ross Sea area, a better inversion result 
was obtained.

The inversion of the thermal structure of the Ross Sea area with the optimized Cursor has a higher resolution in the ocean area than existing models, and it is more in line with the geological structure of the Ross Sea area.

(2) Based on the calculation of heat flow in the Ross Sea area, combined with previous research results, it is speculated that there is a huge amount of natural gas hydrate in the Ross Sea area, and the methane resources in the basin can reach $2.77 \times$ $10^{11} \mathrm{~m}^{3}$.

\section{List of abbreviations}

CPD:Curie-point depth; MCS:Multichannel seismic; VLB:Victoria Land Basin; CT:Central Trough; EB:Eastern Basin; NB:Northern Basin; NCT:Northern Central Trough; TR:Terra Rift.

Authors' contributions: In this study, W.W. was responsible for the initial maritime data collection, post-processing and writing the main manuscript text; W.W. provided the initial idea and conception for this contribution; W.M. was responsible for drawing pictures and some articles; S.M.J, J.W.J and X.P helped with the writing. All authors reviewed the manuscript.

\section{Funding}

This study is supported by the Fundamental Research Funds for Chinese Polar Environment Comprehensive Investigation and Assessment Programmes (CHINARE 2017-01-03 and 2017-04-01) 


\section{Availability of data and materials}

The datasets used and/or analyzed during the current study are available from the corresponding author on any request.

\section{Competing interests}

The authors declare that they have no competing interests.

\section{Author details}

${ }^{1}$ Zhejiang Huadong Construction Engineering Co.,ltd, Hangzhou, 311122, China.

${ }^{2}$ Powerchina Huadong Engineering Corporation LIMITED, Hangzhou, Zhejiang 311122, China.

${ }^{3}$ Zhejiang Academy of Surveying and Mapping, Hangzhou, 311100, China.

\section{Acknowledgements}

Thanks to everyone who provided valuable comments for this article, and thank all the crew of the Xuelong ship for their help during the scientific investigation.

references: 
1 An, Meijian et al., Temperature, lithosphere-asthenosphere boundary, and heat flux beneath the Antarctic Plate inferred from seismic velocities. Journal of Geophysical Research Solid Earth 120 (12), 8720 (2015).

2 Barker, P. F. and Camerlenghi, A., An approach to Antarctic glacial history: the aims of Leg 178. (1999).

3 Chun-Feng Li, Jian Wang, Variations in Moho and Curie depths and heat flow in Eastern and Southeastern Asia. Marine Geophysical Researches (2016).

4 Collett, Timothy S., Energy resource potential of natural gas hydrates. Aapg Bull 86 (11), 1971 (2002).

5 Cooper, A. K., Davey, F. J., and Hinz, K., Liquid hydrocarbons probable under Ross Sea. Oil Gas J 86 (46), 118 (1988).

6 Cooper, A. K. and O'Brien, P. E., Leg 188 synthesis: Transitions in the glacial history of the Prydz Bay region, East Antarctica, from ODP drilling. Proceedings of the Ocean Drilling Program Scientific Results 188, 1 (2004).

7 Cooper, Alan K. and Davey, Frederick J., The Antarctic continental margin : geology and geophysics of the western Ross Sea. (1987).

8 Davey, F. J., Bennett, D. J., and Houtz, R. E., Sedimentary basins of the Ross Sea, Antarctica. New Zealand Journal of Geology E Geophysics (1982).

9 Davies, J. Huw, Global map of solid Earth surface heat flow. Geochemistry Geophysics Geosystems 14 (10), 4608 (2013).

10 Faraday, M. and Davy, H., On Fluid Chlorine. (1823).

11 Geletti, Riccardo and Busetti, Martina, A double bottom simulating 
reflector in the western Ross Sea, Antarctica. Journal of Geophysical Research 116 (B4), B4101 (2011).

12 Houtz, Robert E. and Markl, Rudi G., Seismic Profiler Data Between Antarctica and Australia. (American Geophysical Union (AGU), 1972).

13 Kobayashi, Riki and Katz, Donald L., Methane Hydrate at High Pressure. Journal of Petroleum Technology 1 (03), 66 (1949).

14 Kvenvolden, Keith A., Methane hydrate - A major reservoir of carbon in the shallow geosphere?. Chem Geol 71 (1-3), 41 (1988).

15 Kvenvolden, Keith A. and Redden, George D., Hydrocarbon gas in sediment from the shelf, slope, and basin of the Bering Sea. Geochim Cosmochim Ac 44 (8), 1145 (1980).

16 Lee, Myung W. et al., Method of estimating the amount of in situ gas hydrates in deep marine sediments. Marine E Petroleum Geology 10 (5), 493 (1993).

17 Lifeng W, Xiguang D , Zhibin S, et al. Research on heat flow distribution and gas hydrate economic potential in Antarctic margins. Chinese Journal of Polar Research 25(3), 241-248(2013).

18 Maule, C. F., Purucker, M. E., Olsen, N., and Mosegaard, K., Heat Flux Anomalies in Antarctica Revealed by Satellite Magnetic Data. Science 309 (5733), 464 (2005).

19 Max, M. D. and Lowrie, A., OCEANIC METHANE HYDRATES: A “FRONTIER" GAS RESOURCE. J Petrol Geol (1996). 
20 Mciver, R. D., Hydrocarbon Gases in Canned Core Samples from Leg 28 Sites 271, 272, and 273, Ross Sea. (1975).

21 Miles, P. R., Potential distribution of methane hydrate beneath the European continental margins. Geophys Res Lett 22 (23) (1995).

22 Milkov, Alexei V. and Sassen, Roger, Estimate of gas hydrate resource, northwestern Gulf of Mexico continental slope. Mar Geol 179 (1), 71 (2001). 23 Moscardelli, Lorena, Wood, Lesli, and Mann, Paul, Mass-transport complexes and associated processes in the offshore area of Trinidad and Venezuela. Aapg Bull 90 (7), 1059 (2006).

24 O'Reilly W, Magnetic minerals in the crust of the Earth. Rep Prog Phys 39 (9), 857 (1976).

25 Oldenburg, Dougles W., The Inversion and interpretation of gravity anomalies. Geophysics 39 (4), 526 (1974).

26 Osako, M., Yoneda, A., and Ito, E., Thermal diffusivity, thermal conductivity and heat capacity of serpentine (antigorite) under high pressure. Physics of the Earth E Planetary Interiors 183 (1-2), 229 (2010).

27 Parker, R. L., The Rapid Calculation of Potential Anomalies. Geophysical Journal of the Royal Astronomical Society (1973).

28 Ramalho, M. Fernàndezi Marzána Correiae, Heat flow, heat production, and lithospheric thermal regime in the Iberian Peninsula. Tectonophysics (1998).

29 Sandwell, David T., Biharmonic spline interpolation of GEOSand SEASAT 
altimeter data. Geophys Res Lett 14 (2), (2013).

30 Shi Dou, Sun Chengquan, Zhu Lenian, et al. Research Progress of Natural Gas Hydrate Abroad (Lanzhou University Press) 1-96 (Lanzhou, 1992).

31 Shuan-Shi F, Jin-An G, De-Qing L, et al. A dynamic theory on natural gas hydrate reservoir formation. Natural Gas Geoence 18(6), 819-826 (2007).

32 Villard, P., Dissolution des liquides et des solides dans les gaz. Journal De Physique Théorique Et Appliquée 5 (1), 453 (1896).

33 Wei W, Jin-Yao G, Zhong-Yan S, et al. Formation and storage conditions of gas hydrate and resource assessment of the Ross Sea. Journal of Marine ences 33 (001), 16-24(2015).

34 Y K, K H. Crustal development: Weddell Sea-Ross Sea region. Geological Evolution of Antarctica, 225-230(1991).

35 Youhai Z, Xueguang Z, Zhenquan L, et al. Metallogenic conditions and prospecting prospects of natural gas hydrate in the South China Sea. Acta Petrolei Sinica 22(5), 6-10(2001). 